\title{
Defining ambulatory care sensitive conditions for adults in Portugal
}

\author{
João Sarmento ${ }^{1 *}\left(\mathbb{D}\right.$, João Victor Muniz Rocha ${ }^{1,2}$ and Rui Santana $a^{1,2}$
}

\begin{abstract}
Background: Ambulatory Care Sensitive Conditions (ACSCS) are health conditions for which adequate management, treatment and interventions delivered in the ambulatory care setting could potentially prevent hospitalization. Which conditions are sensitive to ambulatory care varies according to the scope of health care services and the context in which the indicator is used. The need for a country-specific validated list for Portugal has already been identified, but currently no national list exists. The objective of this study was to develop a list of Ambulatory Care Sensitive Conditions for Portugal.

Methods: A modified web-based Delphi panel approach was designed, in order to determine which conditions can be considered ACSCs in the Portuguese adult population. The selected experts were general practitioners and internal medicine physicians identified by the most relevant Portuguese scientific societies. Experts were presented with previously identified ACSC and asked to select which could be accepted in the Portuguese context. They were also asked to identify other conditions they considered relevant. We estimated the number and cost of ACSC hospitalizations in 2017 in Portugal according to the identified conditions.

Results: After three rounds the experts agreed on 34 of the 45 initially proposed items. Fourteen new conditions were proposed and four achieved consensus, namely uterine cervical cancer, colorectal cancer, thromboembolic venous disease and voluntary termination of pregnancy. In 2017 133,427 hospitalizations were for ACSC (15.7\% of all hospitalizations). This represents a rate of 1685 per 100,000 adults. The most frequent diagnosis were pneumonia, heart failure, chronic obstructive pulmonary disease/chronic bronchitis, urinary tract infection, colorectal cancer, hypertensive disease atrial fibrillation and complications of diabetes mellitus.

Conclusions: New ACSC were identified. It is expected that this list could be used henceforward by epidemiologic studies, health services research and for healthcare management purposes. ACSC lists should be updated frequently. Further research is necessary to increase the specificity of ACSC hospitalizations as an indicator of healthcare performance.
\end{abstract}

Keywords: Ambulatory care sensitive conditions, Delphi panel, Portugal

\section{Background}

Ambulatory Care Sensitive Conditions (ACSCs) are health conditions-diagnoses for which timely and effective outpatient care can help to reduce the risks of hospitalization by either preventing the onset of an

\footnotetext{
* Correspondence: joaoccsarmento@gmail.com

${ }^{1}$ NOVA National School of Public Health, Public Health Research Center, Universidade NOVA de Lisboa, Av. Padre Cruz, 1600-560 Lisbon, Portugal Full list of author information is available at the end of the article
}

illness or condition, controlling an acute episodic illness or condition, or managing a chronic disease [1].

One of the first uses of ACSCs to evaluate a healthcare systems' performance was described by Billings et al. [1] in 1993. Its objective was to evaluate the access to healthcare of New York's indigent population. The theory behind this is as follows: if a certain conditiondiagnose can be avoided or controlled, then the need for hospitalization could also be avoided. If the actions to

(c) The Author(s). 2020 Open Access This article is licensed under a Creative Commons Attribution 4.0 International License, which permits use, sharing, adaptation, distribution and reproduction in any medium or format, as long as you give appropriate credit to the original author(s) and the source, provide a link to the Creative Commons licence, and indicate if changes were made. The images or other third party material in this article are included in the article's Creative Commons. licence, unless indicated otherwise in a credit line to the material. If material is not included in the article's Creative Commons licence and your intended use is not permitted by statutory regulation or exceeds the permitted use, you will need to obtain permission directly from the copyright holder. To view a copy of this licence, visit http://creativecommons.org/licenses/by/4.0/ The Creative Commons Public Domain Dedication waiver (http://creativecommons.org/publicdomain/zero/1.0/) applies to the data made available in this article, unless otherwise stated in a credit line to the data. 
avoid it can be taken in the ambulatory setting, then lack of access or effectiveness of ambulatory care should result in more hospitalizations.

This means that measuring ACSC hospitalizations can indirectly indicate how well the ambulatory care setting is performing. However, this information alone is not enough to accurately identify causes of poor performance. At least two largely different dimensions need to be taken into consideration. Firstly, individuals need to have access to ambulatory care in order to have certain conditions-diagnoses addressed. Secondly, the ambulatory setting needs to be effective.

When using ACSC hospitalizations as a performance indicator, lower number/rates of hospitalizations generally mean that ambulatory care is performing well. If numbers are higher it indicates that there could be a problem in access, effectiveness or both. This is the simplistic approach. The utility and information provided by ACSC as an indicator depends on further characteristics of the context in which they are measured. Nedel et al. [2] proposed major categories of influencing factors: Geographical characteristics; Sociodemographic characteristics and Model of care. The first category includes variables such as hospital proximity [3] or lower populational density and isolation [4], which increases the number of ACSC hospitalizations. Sociodemographic characteristics such as higher age, lower education, lower income or higher unemployment are also associated with higher rates of ACSC hospitalizations [4-8]. Comorbidities are an important risk factor [9], increasing the risk of hospitalization with each chronic condition or body system affected. Finally, the model of care has a significant impact on this indicator. Not only the organization and availability of healthcare providers has an impact, with lower rates where there is higher availability $[4,10]$, but also intrinsic characteristics of the model of care such as continuity of care plays important roles. Menec et al. [11] described that patients with more than $75 \%$ of consultations by the same family physician have fewer ACSC hospitalizations. Access to hospital beds also influences this indicator. If there is severe shortage of hospital beds then, even if the ambulatory care setting is not performing well, there will not be an increase in ACSC hospitalizations. On the other hand, if there is an excess of hospital beds, even if the ambulatory care setting is performing well, there might be an incentive to admit certain conditions and therefore increase ACSC hospitalizations [2].

ACSC hospitalizations are only measurable after they have occurred. However, when they occur the window of opportunity to avoid them in ambulatory care has already elapsed. Therefore, this means that measuring ACSC hospitalizations depends on the availability of hospital discharge data with enough detail. The key information is the most responsible diagnosis of each hospitalization, which if included in an ACSC list flags the hospitalization as potentially avoidable. Further information is also relevant to eventually detail other relevant determinants of hospitalization, such as patients' age [3] and number of comorbidities [9].

Which conditions are sensitive to ambulatory care varies according to the scope of health care services and the context in which the indicator is used $[2,12]$. Consequently, different methods to identify such hospitalizations have been developed worldwide. Different ACSCs lists have been developed since Billings et al. [1] in 1993, such as Caminal et al. [3], Brown et al. [13], Canadian Institute for Health Information (CIHI) [14], Page et al. [15], Purdy et al. [12], Alfradique et al. [16], Freund et al. [17], Sundmacher et al. [18] and the United States Agency for Healthcare Research and Quality (AHRQ) [19].

The process of defining ACSC lists usually starts with a literature review seeking to identify conditions with a potential relation to ambulatory care, followed by processes of discussion and validation with experts. This method aims to reach a consensus on which conditions are sensitive to ambulatory care according to the organization of care, disease mechanisms and prevalence, socioeconomic and cultural characteristics of the population and the patient course within the health system $[2,12]$.

Additionally, the inclusion of conditions usually follows specific criteria, being the Solberg and Weissman the most commonly used $[20,21]$. These criteria include: (i) the existence of previous studies, (ii) clarity in the definition and coding of diagnoses, (iii) relevance for public health (a hospitalization rate of least $1 / 10,000$ population), (iv) if the diagnosis is potentially avoidable by timely and effective ambulatory care and (v) the necessity of hospitalization.

The lists of ACSC developed in different countries are used by national and international institutions as a proxy for health care quality assessment. The WHO Regional Office for Europe produced a working document summarizing the evidence for using ACSC as an indicator for health care performance in the dimensions of access, quality, coordination and efficiency [22]. The OECD included hospitalizations for ACSC in the list of indicators for health care performance, under the argument that high hospitalization rates indicate possibilities of improving quality and reaching substantial cost savings, given that better primary care is provided [23, 24]. The NHS in England has been reporting information on ACSC as part of the NHS Outcomes Framework to monitor quality of care based on conditions sensitive to its primary health care [25] and has associated incentives to improve performance for certain ACSCs 
[26]. The AHRQ developed quality indicators for health care consisting of hospitalizations for ACSC [19], with conditions selected based on discussion of evidence in the dimensions of face validity, precision, minimum bias, construct validity, if it fosters true quality improvement and prior uses [27]. The ACSC list developed in Brazil is available for primary health care evaluation purposes [28]. In Portugal ACSS uses the rate of ACSC hospitalizations as an indicator of healthcare quality in vertical integrated healthcare units since 2016, and the ministry of health included this indicator, in a wider framework of evaluation, of primary care in 2017 [29].

The need for a country-specific validated list for Portugal has already been identified [30], however such tool has not been developed yet. Previous studies in Portugal have used different lists of ACSCs [31-34]. Some studies have indicated that, according to the list developed by Caminal et al. [3] for Spain, rates of ACSC hospitalizations have increased during the last years in Portugal [34-36]. However, according to the CIHI list [14], the rates have declined [32, 36]. The reason for such difference is in the methodology applied: while the Spanish list includes acute and chronic conditions, the CIHI list only contains chronic conditions. There is variation on rates of hospitalizations for ACSCs according to which conditions are selected and analysed [12, 30, 37, 38].

It was estimated that ACSCs represented $12.3 \%$ of all hospitalizations registered in mainland Portugal in 2013 [35]. These hospitalizations were concentrated in five main conditions: pneumonia, congestive obstructive pulmonary disease (COPD), heart failure, hypertensive heart diseases and kidney and urinary tract infections. Around $7.3 \%$ of the hospitalizations for ACSCs were of repeated patients [39].

Despite the complex framework of ACSCs determinants [2, 3], this is a valuable tool for health care assessment; it has been increasingly discussed not only at the academic level but also adopted by national health systems and international organizations as an indicator of performance $[14,19,22,40,41]$.

The objective of this study was to develop a list of Ambulatory Care Sensitive Conditions for Portugal. A secondary goal was to identify ACSC hospitalizations based on the developed list.

\section{Methods}

A modified Delphi panel approach was designed [1, $3,16,18]$, in order to determine which conditions can be considered ACSCs in the Portuguese adult population. It was web-based and asynchronous, being the answers submitted by each expert via a webbased form during a specified period of time. The experts were selected according to the following criteria:

a) Specialist in General and Family Medicine (GP) or Internal Medicine (IM);

b) Clinically active in the National Health Service;

c) Preferably with an active academic collaboration;

We designed the mix of experts to be $75 \%$ GP and $25 \%$ IM. Being clinically active in the NHS was considered essential to assure the experts' knowledge of the regularly available resources. The preferable active academic collaboration was included to increase the experts' ability to understand the objectives and methods of this panel. The experts were selected, according to the defined criteria, by the most important scientific societies of each specialty, namely the Portuguese Association of General and Family Medicine (APMGF) and the Portuguese Society of Internal Medicine (SPMI). A total of 84 experts were invited to participate through an email invitation letter which included a description of the panels' objective and methods. After agreeing to participate each expert was sent a link to a web-based form (institutional SurveyMonkey account). The panel lasted from September 2017 to May 2018.

Firstly, a brief conceptual framework of ACSC and the difference between avoidable and adequate hospitalization was delivered. The first question then was "In your opinion, and given the current legis artis, would you consider possible to avoid the need for hospital admission in Portugal in the following clinical conditions?". Experts were presented with a list of all previously identified ACSCs, for which a yes/no/don't know box was available to be ticked as well as a commentary box, should the experts wish to discuss their answer. This list of conditions was compiled in a preparatory stage by searching Pubmed with the keywords "Ambulatory Care Sensitive Conditions", "Avoidable admissions", and "Avoidable hospitalizations". The relevant results of this search are described in Table 1.

The second question was "In your opinion, and given the current legis artis, would you consider possible to avoid the need for hospital admission in Portugal in any other clinical condition not previously mentioned?". Experts had an open answer box to fill. In each round, there was a final commentary box available for questions not directly related to specific conditions.

The consensus level was defined as $75 \%$ after a maximum of three rounds $[3,18]$. The percentual level of consensus was calculated by dividing the frequency of answers by the number of respondents in each round, multiplied by 100 . To allow for the items marginally over the consensus limit to still be discussed in the following rounds the clinical conditions with a level of 
Table 1 Summary of relevant papers identified during the literature review to catalogue previously defined ACSCS

\begin{tabular}{|c|c|c|c|c|}
\hline Author / Institution & Country & Year & Number ACSC & Method \\
\hline Weissman, Gatsonis e Epstein [21] & USA & 1992 & 12 & Literature review + expert panel evaluation \\
\hline $\begin{array}{l}\text { Billings et al. / United Hospital Fund of New } \\
\text { York [1] }\end{array}$ & USA & 1993 & 28 & Modified Delphi panel (6 physicians) \\
\hline Sanderson e Dixon [42] & UK & 2000 & 30 & Modified Delphi panel (3 physician panels) \\
\hline $\begin{array}{l}\text { Davies et al. / Agency for Healthcare Research } \\
\text { and Quality [27] }\end{array}$ & USA & 2001 & $\begin{array}{l}16 \text { Prevention Quality } \\
\text { Indicators (PQI) }\end{array}$ & $\begin{array}{l}\text { Set of measures to identify ACSC. Based } \\
\text { on literature review, empirical testing and } \\
\text { consensus among expert panels. }\end{array}$ \\
\hline $\begin{array}{l}\text { Caminal et al. / Universidade Autónoma de } \\
\text { Barcelona [3] }\end{array}$ & Spain & 2001 & 35 & Delphi Panel (44 experts) \\
\hline Brown et al. / University of Oxford [13] & Canada & 2001 & 27 & $\begin{array}{l}\text { Delphi panel (13 experts) + Modified Delphi panel } \\
(12 \text { experts) + questionnaire panel ( } 11 \text { experts) }\end{array}$ \\
\hline Purdy et al. / Bristol University [12] & UK & 2009 & 19 & Literature review. \\
\hline Alfradique et al. [16] & Brazil & 2009 & 20 & Literature review + Experts consultation \\
\hline Walker et al. [43] & Canada & 2009 & 18 & Administrative data + Expert consensus (9 experts) \\
\hline Freund et al. [17] & Germany & 2013 & 26 & AHRQ + expert selection \\
\hline Eggli et al. [44] & Switzerland & 2014 & 19 & $\begin{array}{l}\text { Based on Purdy et al. + update of ICD-10 codes for } \\
\text { specific conditions }\end{array}$ \\
\hline Naumann, Augustin e Sundmacher [45] & Germany & 2014 & 32 & $\begin{array}{l}\text { Based on Purdy et al. }+2 \text { potentially relevant } \\
\text { diagnoses }\end{array}$ \\
\hline Sundmacher et al. [18] & Germany & 2015 & 22 & Literature review + Delphi panel (40 experts) \\
\hline
\end{tabular}

consensus lower than $85 \%$ were included in the following rounds. After the first and second rounds, each expert was sent an individual spreadsheet with the aggregate results of the entire panel as well as his/her answers for each clinical condition. In the second and third rounds, each non-consensual condition was accompanied by a summary of the experts' comments on the previous round. These summaries were convened after discussion between two researchers (JS and RS) and were anonymised. The clinical conditions not present in previous lists were identified by experts in the first round and still submitted to three rounds of discussion before the end of the panel.

After the experts validated the list, we identified hospitalizations for ACSC in Portugal in 2017, for the population aged 18 years or older, according to the principal diagnosis. We used the hospitalizations database provided by the Portuguese Central Administration of the Health System [Administração Central do Sistema de Saúde-ACSS]. We compiled two lists. The core list is composed by the conditions that fulfilled the criteria ii to iv proposed by Solberg and Weissman [20, 21]. Also an extended list is presented including all conditions agreed by the experts, despite not fulfilling all Solberg and Weissman criteria.

Costs of hospitalizations for ACSC were used to estimated potential healthcare savings associated to these events, according to the list obtained. Official hospitalization prices were used as proxy for costs, as done in previous studies in other countries [38, 46-48].
These prices are defined by Diagnosis Related Groups (all patients refined diagnosis related groups version 31.0) and severity of the condition, according to values published by the Ministry of Health [49].

\section{Results}

Of the 55 invited GPs, 28 accepted to participate (50.9\%) and 25 completed all rounds (89.3\%). Regarding the Internal Medicine physicians, 29 were invited, 5 accepted to participate $(17.2 \%)$ and 4 completed all rounds (80\%).

Table 2 shows the panel's results. In the first round, there was consensus (over 85\%) in 22 of the 45 items (48.9\%). In the second round, 7 further items achieved consensus. Finally, after three rounds, consensus (over $75 \%$ ) was achieved for 34 items, leaving 11 nonconsensual items (22.2\%).

Table 3 shows the potentially new ACSCs suggested by the experts. Out of fourteen new conditions, four achieved consensus (over 75\%) after three rounds and were included as ACSCs.

Table 4 shows the number of hospitalizations for ACSCs in Portugal in 2017, for population aged 18 years or older, the hospitalization rate per 10,000 people and the ICD10 codes used for this identification. The conditions that fulfill the criteria ii to iv by Solberg and Weissman are in bold, and those compose the core list. In 2017, there were 847,609 hospitalizations of people aged 18 years or older; out of these, 133,427 were for ACSC (15.7\% of all hospitalizations). This represents a rate of 1685 hospitalization per 100,000 adults. The most 
Table 2 Delphi Panel Results, pre-existing ACSCs

\begin{tabular}{|c|c|c|c|}
\hline Condition & 1st round & 2nd round & 3 rd round \\
\hline Acute myocardial infarction & $22,86 \%$ & $20,00 \%$ & $48,28 \%$ \\
\hline Acute otitis media & $97,14 \%$ & & \\
\hline Acute pharyngitis & $97,14 \%$ & & \\
\hline Acute poliomyelitis & $62,86 \%$ & $86,67 \%$ & \\
\hline Acute sinusitis & $91,43 \%$ & & \\
\hline Acute skin infections & $88,57 \%$ & & \\
\hline Acute tonsillitis & $97,14 \%$ & & \\
\hline Appendicitis with complications $^{a}$ & $20,00 \%$ & $10,00 \%$ & \\
\hline Asthma & $88,57 \%$ & & \\
\hline Atrial fibrillation & $71,43 \%$ & $76,67 \%$ & $82,76 \%$ \\
\hline Chronic obstructive pulmonary disease / chronic bronchitis & $88,57 \%$ & & \\
\hline Dehydration / Hydroelectrolytic changes & $80,00 \%$ & $83,33 \%$ & $86,21 \%$ \\
\hline Dementia & $62,86 \%$ & $70,00 \%$ & $75,86 \%$ \\
\hline Dental and oral cavity pathology & $91,43 \%$ & & \\
\hline Diabetes mellitus (acute and chronic complications) & $85,71 \%$ & & \\
\hline Diphtheria & $71,43 \%$ & $93,33 \%$ & \\
\hline Epilepsy and seizures & $57,14 \%$ & $53,33 \%$ & $48,28 \%$ \\
\hline Folate deficiency anemia & $91,43 \%$ & & \\
\hline Gangrene & $25,71 \%$ & $43,33 \%$ & $72,41 \%$ \\
\hline Gastroenteritis & $91,43 \%$ & & \\
\hline Heart failure & $82,86 \%$ & $90,00 \%$ & \\
\hline HBV acute infection & $77,14 \%$ & $90,00 \%$ & \\
\hline HBV chronic infection & $85,71 \%$ & & \\
\hline Hypertensive disease & $97,14 \%$ & & \\
\hline Infectious parotitis & $82,86 \%$ & $86,67 \%$ & \\
\hline Influenza & $88,57 \%$ & & \\
\hline Iron deficiency anemia & $91,43 \%$ & & \\
\hline Ischemic myocardial disease & $65,71 \%$ & $70,00 \%$ & $65,52 \%$ \\
\hline Measles & $82,86 \%$ & $86,67 \%$ & \\
\hline Meningitis by $\mathrm{H}$. influenzae & $48,57 \%$ & $63,33 \%$ & $48,28 \%$ \\
\hline Nutritional deficiencies & $82,86 \%$ & $73,33 \%$ & $68,97 \%$ \\
\hline Pelvic inflammatory disease & $65,71 \%$ & $66,67 \%$ & $55,17 \%$ \\
\hline Perforated / bleeding digestive ulcer & $37,14 \%$ & $40,00 \%$ & $65,52 \%$ \\
\hline Periamygdaline abscess & $60,00 \%$ & $56,67 \%$ & $51,72 \%$ \\
\hline Pneumonia & $88,57 \%$ & & \\
\hline Rheumatic fever & $65,71 \%$ & $76,67 \%$ & $68,97 \%$ \\
\hline Rubella & $88,57 \%$ & & \\
\hline Syphilis & $97,14 \%$ & & \\
\hline Tetanus & $68,57 \%$ & $86,67 \%$ & \\
\hline Tuberculosis & $77,14 \%$ & $83,33 \%$ & $89,66 \%$ \\
\hline Upper respiratory tract infection & $97,14 \%$ & & \\
\hline Urinary tract infections & $88,57 \%$ & & \\
\hline Urinary tract infections in pregnancy & $85,71 \%$ & & \\
\hline Vitamin B12 deficiency anemia & $91,43 \%$ & & \\
\hline Whooping cough & $80,00 \%$ & $83,33 \%$ & $79,31 \%$ \\
\hline
\end{tabular}


Table 3 Delphi Panel Results, newly proposed conditions

\begin{tabular}{llll}
\hline Condition & 1 st round & 2nd round & 3 rd round \\
\hline Abortion complications & $46,67 \%$ & $55,17 \%$ & $34,48 \%$ \\
Alcoholic liver disease & $70,00 \%$ & $82,76 \%$ & $72,41 \%$ \\
Bipolar disorder & $70,00 \%$ & $62,07 \%$ & $58,62 \%$ \\
Colorectal cancer & $50,00 \%$ & $68,97 \%$ & $\mathbf{7 5 , 8 6 \%}$ \\
Hepatitis C & $73,33 \%$ & $82,76 \%$ & $68,97 \%$ \\
HIV infection & $76,67 \%$ & $75,86 \%$ & $68,97 \%$ \\
Lung cancer & $50,00 \%$ & $68,97 \%$ & $62,07 \%$ \\
Melanoma & $60,00 \%$ & $65,52 \%$ & $55,17 \%$ \\
Occupational accidents & $56,67 \%$ & $48,28 \%$ & $48,28 \%$ \\
Occupational diseases & $63,33 \%$ & $58,62 \%$ & $62,07 \%$ \\
Schizophrenia & $66,67 \%$ & $58,62 \%$ & $55,17 \%$ \\
Thromboembolic venous disease ${ }^{a}$ & $56,67 \%$ & $62,07 \%$ & $\mathbf{8 2 , 7 6 \%}$ \\
Uterine cervical cancer $_{\text {Voluntary termination of pregnancy }}$ & $56,67 \%$ & $\mathbf{7 5 , 8 6 \%}$ & $\mathbf{7 5 , 8 6 \%}$ \\
\hline
\end{tabular}

aexcluding pulmonary thromboembolism

frequent diagnosis were pneumonia, heart failure, chronic obstructive pulmonary disease/chronic bronchitis, urinary tract infection, colorectal cancer, hypertensive disease atrial fibrillation and complications of diabetes mellitus.

Table 5 shows the estimated costs of hospitalizations for ACSC according to the core list. It was estimated that, in 2017, hospitalizations for ACSC in Portugal had a total cost of 352 million euros, indicating substantial healthcare costs might have been avoided. Around 48\% of the total costs were for pneumonia and heart failure, and these two conditions were the most frequent. Hypertensive disease and colorectal cancer corresponded to $22 \%$ of the total costs: the average costs of each hospitalization for these conditions are the highest among all conditions (5533 and 4067 euros per hospitalization, respectively), given the complexity of these diseases.

Table 6 compares the list obtained by this study with some of the lists previously developed and in current use in other countries. It is important to mention that this table contains the broader identification of diagnostics, but specific ICD codes may vary between lists.

\section{Discussion}

This section will start with the methods' discussion followed by the results' discussion. To finalize we will briefly discuss this paper's contribution to science and healthcare, as well as important underlying questions about using ACSCs as an indicator.

Regarding methods we have developed the list for the Portuguese context using the Delphi Panel method. All lists of ACSC have been developed using experts opinion to some extent, being the Delphi panel method the most frequently used $[3,16,18]$. The reason for this is the necessary evaluation of comprehensive and complex disease mechanisms and diagnostic/treatment pathways in order to determine if a condition can be avoided and/or treated in the ambulatory setting. No other method is described. The experts' selection process is extremely important for the panels' conclusions. Therefore, we intentionally mixed GPs with IMs since their perspectives are complementary. While the first are responsible for most ambulatory care in Portugal, therefore understanding the resources available in the ambulatory setting, the latter are the most responsible for hospital admission decisions and have the end-of-the-line perspective on the pathways that lead to an ACSC hospitalization. To ensure the experts quality we defined clear selection criteria and arranged for a peer-selection by the most relevant Portuguese scientific societies in each specialty. The difference in the invitation acceptance rate between GPs (50.9\%) and IMs (17.2\%) is very likely related to the higher familiarity with the concept of ACSC by GPs, once these are used as a performance indicator of primary care by local, regional and national authorities. The final mix of $86 \%$ GPs was higher than initially designed. However, the IMs were fairly active during the several rounds and positively contaminated the discussion on several items.

In terms of results the experts proposed fourteen new ACSCs having four conditions achieved consensus, namely uterine cervical cancer, colorectal cancer, thromboembolic venous disease and voluntary termination of pregnancy. For both type of cancers, the experts referred to the screening undertaken in primary care as the technology that might avoid the necessity of hospitalization. The reasoning is that early detected 
Table 4 Portuguese ACSCs list, Core (in bold) and extended, ICD 10 codes and frequency of diagnosis, Portugal 2017

\begin{tabular}{|c|c|c|c|}
\hline Condition & $I C D 10$ & $\begin{array}{l}\mathrm{N} \text { of } \\
\mathrm{ACSHS}\end{array}$ & $\begin{array}{l}\text { Hospitalization rate } \\
\text { (per } 10,000 \text { population) }\end{array}$ \\
\hline Acute otitis media ${ }^{a}$ & H65.0, H65.1, H66.0 & 208 & 0.26 \\
\hline Acute pharyngitis $^{a}$ & $\mathrm{~J} 02$ & 28 & 0.03 \\
\hline Acute poliomyelitis $^{a}$ & A80 & 1 & 0.00 \\
\hline Acute sinusitis $^{a}$ & J01 & 111 & 0.13 \\
\hline Acute skin infections & L01-L04, L08 & 4158 & 5.25 \\
\hline Acute tonsillitis $^{a}$ & J03 & 366 & 0.46 \\
\hline Asthma & $\mathrm{J} 45, \mathrm{~J} 46$ & 1513 & 1.91 \\
\hline Atrial fibrillation & 148 & 6218 & 7.85 \\
\hline $\begin{array}{l}\text { Chronic obstructive pulmonary } \\
\text { disease / chronic bronchitis }\end{array}$ & J40-J44, J47 & $\begin{array}{l}10 \\
476\end{array}$ & 13.23 \\
\hline Colorectal cancer $^{\mathbf{b}}$ & $\mathrm{C} 18-\mathrm{C} 20, \mathrm{C} 21.8$ & 9664 & 12.29 \\
\hline $\begin{array}{l}\text { Dehydration / Hydroelectrolytic } \\
\text { changes }\end{array}$ & E86, E87.6 & 2169 & 2.73 \\
\hline Dementia & F01, F03, G30, G31.0, G31.8 & 1667 & 2.11 \\
\hline Dental and oral cavity pathology & A69.1, K02-K06, K08, K09, K12-K14 & 1566 & 1.98 \\
\hline Depression & F32, F33 & 3063 & 3.87 \\
\hline Diabetes mellitus (complications) & $\begin{array}{l}\text { E10.0, E10.1, E10.5, E10.6, E10.8, E10.9, E11.0, E11.1, E11.5, E11.6, E11.8, E11.9, } \\
\text { E12.0, E12.1, E12.5, E12.6, E12.8, E12.9, E13.0, E13.1, E13.5, E13.6, E13.8, E13.9, } \\
\text { E14.0, E14.1, E14.5, E14.6, E14.8, E14.9, E15 }\end{array}$ & 5409 & 6.83 \\
\hline Diphtheria $^{a}$ & A36 & 0 & 0.00 \\
\hline Folate deficiency anemia ${ }^{a}$ & D52 & 35 & 0.04 \\
\hline Gastroenteritis & A00 - A09 & 2412 & 3.05 \\
\hline Heart failure & $111.0,113.0,113.2,150, J 81$ & $\begin{array}{l}23 \\
862\end{array}$ & 32.66 \\
\hline HBV acute infection ${ }^{a}$ & B16 & 22 & 0.03 \\
\hline HBV chronic infection ${ }^{\mathrm{a}}$ & B18.0, B18.1 & 58 & 0.07 \\
\hline Hypertensive disease & I10, I11.9, I12, I13.1, I13.9, I15, I60, 161, I64, I67.4 & 6733 & 8.50 \\
\hline Infectious parotitis ${ }^{a}$ & B26 & 41 & 0.05 \\
\hline Influenza & J9, J10, J11 & 842 & 1.06 \\
\hline Iron deficiency anemia & D50 & 1588 & 2.00 \\
\hline Measles $^{a}$ & B05 & 4 & 0.00 \\
\hline Obesity & E66 & 2635 & 3.33 \\
\hline Pneumonia & J13, J14, J15.3, J15.4, J15.7, J15.8, J15.9, J16.0 J16.8, J18 & $\begin{array}{l}37 \\
204\end{array}$ & 46.98 \\
\hline Rubella $^{a}$ & B06 & 1 & 0.00 \\
\hline Syphilis $^{a}$ & A51 - A53 & 112 & 0.14 \\
\hline Tetanus $^{a}$ & A33 - A35 & 1 & 0.00 \\
\hline Thromboembolic venous disease $e^{a, b}$ & $180,182.2,182.3,182.8,182.9$ & 231 & 0.29 \\
\hline Tuberculosis $^{\mathrm{a}}$ & A15-A17 & 778 & 0.98 \\
\hline Upper respiratory tract infection ${ }^{a}$ & J06 & 254 & 0.32 \\
\hline Uterine cervical cancer ${ }^{\mathbf{b}}$ & $\mathrm{C} 53$ & 929 & 1.17 \\
\hline Urinary tract infections & N10-N12, N30.0, N30.8, N30.9 & $\begin{array}{l}10 \\
347\end{array}$ & 13.07 \\
\hline Urinary tract infections in pregnancy ${ }^{a}$ & O23.0, O23.1, O23.2, O23.3, O23.4, O23.9 & 599 & 0.76 \\
\hline Vitamin B12 deficiency anemia ${ }^{a}$ & D51 & 109 & 0.13 \\
\hline $\begin{array}{l}\text { Voluntary termination of } \\
\text { pregnancy }^{\mathbf{b}}\end{array}$ & Z332 & 972 & 1.23 \\
\hline Whooping cough ${ }^{a}$ & A37 & 2 & 0.00 \\
\hline
\end{tabular}

\footnotetext{
a Do not fulfill criteria iii
}

${ }^{b}$ Suggested by experts 
Table 5 Costs of hospitalizations for ACSC

\begin{tabular}{|c|c|c|c|}
\hline Condition & Cost (in euros) & $\%$ Total & Average cost per hospitalization (in euros) \\
\hline Acute Skin Infections & $7,235,584$ & 2.06 & 1740 \\
\hline Asthma & $2,253,453$ & 0.64 & 1489 \\
\hline Atrial fibrillation & $10,968,413$ & 3.12 & 1764 \\
\hline Chronic obstructive pulmonary disease / chronic bronchitis & $23,196,097$ & 6.60 & 2214 \\
\hline Colorectal cancer & $39,303,605$ & 11.18 & 4067 \\
\hline Dehydration / Hydroelectrolytic Changes & $3,798,308$ & 1.08 & 1751 \\
\hline Dementia & $4,248,041$ & 1.21 & 2548 \\
\hline Dental and oral cavity pathology & $2,362,121$ & 0.67 & 1508 \\
\hline Depression & $4,874,647$ & 1.39 & 1591 \\
\hline Diabetes mellitus (complications) & $12,961,718$ & 3.69 & 2396 \\
\hline Gastroenteritis & $4,283,792$ & 1.22 & 1776 \\
\hline Heart failure & $72,133,697$ & 20.51 & 3023 \\
\hline Hypertensive disease & $37,251,495$ & 10.59 & 5533 \\
\hline Influenza & $2,188,947$ & 0.62 & 2600 \\
\hline Iron deficiency anemia & $2,335,446$ & 0.66 & 1470 \\
\hline Obesity & $5,428,646$ & 1.54 & 2060 \\
\hline Pneumonia & $97,477,559$ & 27.72 & 2620 \\
\hline Urinary Tract Infections & $17,016,441$ & 4.84 & 1645 \\
\hline Uterine cervical cancer & $1,726,860$ & 0.49 & 1858 \\
\hline Voluntary termination of pregnancy & 624,279 & 0.18 & 642 \\
\hline Total & $351,669,148$ & 100 & 2597 \\
\hline
\end{tabular}

conditions might obliviate the need for more complex interventions that require hospital admission. This does not, however, mean that all cancers and therefore all admissions for cancer are avoidable. Regarding thromboembolic venous disease, experts identified the early diagnosis and treatment as capable of avoiding hospitalizations. Finally, voluntary termination of pregnancy was considered avoidable if effective and timely family planning is accessible. All of these conditions verified the relevance for Public Health criterion proposed by Solberg and Weissman (hospitalization rate higher than $1 /$ 10.000 hab) being colorectal cancer, in fact, the fifth highest rate of ACSC hospitalization in Portugal in 2017. Although these criteria have been widely accepted, we do not agree that Public Health relevance should be strictly reduced to a hospitalization rate. For this reason, we propose two lists of ACSC, the core list including only the conditions that verify the hospitalizations rate criterion, and the extend list where all conditions considered ACSC by experts are included.

It is also noteworthy that other four conditions strongly related to behavioural and lifestyle decisions were newly proposed and almost reached consensus, namely alcoholic liver disease, hepatitis C, HIV infection and lung cancer. The health promotion capacity of primary care was identified as the technology that might prevent the onset of these diseases and therefore the need for hospitalization. It is also relevant to discuss that the recent pharmacological innovation for the treatment of HIV and hepatitis $C$ viruses infection might render the need for hospitalization growingly residual.

Another important discussion topic is the consensus in not considering appendicitis with complication an ACSC and the lack of consensus in further nine previously considered conditions. This fact elicits the discussion on the context specificities to which is important to adapt the ACSC lists. This may also reflect the limitation of using experts' opinion to define ACSCs. In summary, the influx and efflux of conditions considered ACSC reflects the importance of regularly updating the lists. Nearly all the previous lists used in the comparison in Table 6 were developed more than 10 years ago. The constant development of knowledge, technology and healthcare design demands that the ACSC lists are updated more regularly.

Among the lists compared, the oldest one was proposed by Billings in 1993 [1]. Out of the 16 conditions proposed by Billings, only 7 are included in the list developed for Portugal, reflecting the need of updating lists. The lists proposed by the AHRQ and CIHI are the ones with less conditions included, while the expanded 
Table 6 Comparison of Portuguese list with previous lists

\begin{tabular}{|c|c|c|c|c|c|c|c|c|c|c|}
\hline Conditions & Portugal & Alfradique & AHRQ & Billings & Caminal & $\mathrm{ClHI}$ & Freund & Page & Purdy & Sundmacher \\
\hline Acute otitis media & & $x$ & & $x$ & & & & $x$ & $x$ & $x$ \\
\hline Acute pharyngitis & & $x$ & & $x$ & & & & $x$ & $x$ & $x$ \\
\hline Acute poliomyelitis & & & & & $x$ & & $x$ & $x$ & $x$ & $x$ \\
\hline Acute sinusitis & & $x$ & & & & & & & & $x$ \\
\hline Acute skin infections & $x$ & $x$ & & $x$ & & & $x$ & $x$ & $x$ & $x$ \\
\hline Acute tonsillitis & & $x$ & & $x$ & & & & $x$ & $x$ & $x$ \\
\hline Angina & & $x$ & & $x$ & $x$ & $x$ & $x$ & $x$ & $x$ & \\
\hline Asthma & $x$ & $x$ & $x$ & $x$ & & $x$ & $x$ & $x$ & $x$ & $x$ \\
\hline Atrial fibrillation & $x$ & & & & & & $x$ & & & \\
\hline Uterine cervical cancer & $x$ & & & & & & & & & \\
\hline Chronic obstructive pulmonary disease / chronic bronchitis & $x$ & $x$ & $x$ & & & $x$ & $x$ & $x$ & $x$ & $x$ \\
\hline Colorectal cancer & $x$ & & & & & & & & & \\
\hline Dehydration / Hydroelectrolytic Changes & $x$ & $x$ & $x$ & & $x$ & & $x$ & $x$ & $x$ & $x$ \\
\hline Dementia & $x$ & & & & & & & & & $x$ \\
\hline Dental and oral cavity pathology & $x$ & & & $x$ & & & $x$ & $x$ & $x$ & $x$ \\
\hline Depression & $x$ & & & & & & & & & $x$ \\
\hline Diabetes mellitus (acute and chronic complications) & $x$ & $x$ & $x$ & & $x$ & $x$ & $x$ & $x$ & $x$ & $x$ \\
\hline Diphtheria & & $x$ & & & $x$ & & $x$ & $x$ & $x$ & \\
\hline Epilepsy & & $x$ & & $x$ & & $x$ & $x$ & $x$ & $x$ & \\
\hline Folate deficiency anemia & & & & & & & & & & $x$ \\
\hline Gangrene & & & & & $x$ & & $x$ & $x$ & $x$ & \\
\hline Gastroenteritis & $x$ & $x$ & & $x$ & & & $x$ & & & $x$ \\
\hline Heart failure & $x$ & $x$ & $x$ & $x$ & $x$ & $x$ & $x$ & $x$ & $x$ & $x$ \\
\hline HVB acute infection & & $x$ & & & & & $x$ & $x$ & $x$ & $x$ \\
\hline HVB chronic infection & & & & & & & $x$ & $x$ & $x$ & $x$ \\
\hline Hypertension & $x$ & $x$ & $x$ & & $x$ & $x$ & $x$ & $x$ & $x$ & $x$ \\
\hline Infectious Parotitis & & $x$ & & & & & & $x$ & $x$ & $x$ \\
\hline Influenza & $x$ & & & & & & $x$ & $x$ & $x$ & $x$ \\
\hline Iron deficiency anemia & $x$ & $x$ & & $x$ & & & $x$ & $x$ & $x$ & $x$ \\
\hline Measles & & $x$ & & & & & $x$ & $x$ & $x$ & $x$ \\
\hline Obesity & $x$ & & & & & & & & & $x$ \\
\hline Pelvic inflammation & & $x$ & & $x$ & $x$ & & $x$ & $x$ & $x$ & $x$ \\
\hline Perforated/bleeding ulcer & & $x$ & & & $x$ & & $x$ & $x$ & $x$ & $x$ \\
\hline Pneumonia & $x$ & $x$ & $x$ & $x$ & $x$ & & $x$ & $x$ & & $x$ \\
\hline Rubella & & $x$ & & & & & $x$ & $x$ & $x$ & $x$ \\
\hline Syphilis & & $x$ & & & $x$ & & & & & $x$ \\
\hline Tetanus & & $x$ & & $x$ & $x$ & & $x$ & $x$ & $x$ & $x$ \\
\hline Thromboembolic venous disease & $x$ & & & & & & & & & \\
\hline Tuberculosis & & $x$ & & $x$ & $x$ & & & $x$ & & $x$ \\
\hline Upper respiratory tract infection & & $x$ & & $x$ & & & & $x$ & $x$ & $x$ \\
\hline Urinary Tract Infections & $x$ & $x$ & $x$ & & $x$ & & & & $x$ & $x$ \\
\hline Urinary tract infections in pregnancy & & $x$ & & & & & & & & $x$ \\
\hline Vitamin B12 deficiency anemia & & & & & & & & & & $x$ \\
\hline Voluntary termination of pregnancy & $x$ & & & & & & & & & \\
\hline Whooping cough & & $x$ & & & & & $x$ & $x$ & $x$ & $x$ \\
\hline
\end{tabular}


list obtained for Portugal is composed of 40 conditions that include acute, chronic and vaccine-preventable diseases.

The rates of hospitalization in this paper are in line with previous studies regarding the most frequent ACSCs in Portugal being pneumonia, COPD, cardiovascular diseases, urinary tract infection and diabetes $[35,50]$. These conditions are included in most of the previous lists presented in Table 6.

Using the developed list, we identified that $15.7 \%$ of all hospitalizations were for ACSC. This is higher than what was found in previous studies, due to the inclusion of more conditions. Previous studies identified 4.4\% [36], 9.9\% [31] and 12.3\% [35] between 2012 and 2015. These studies used different lists, therefore the differences between results.

To estimate the ACSC hospitalizations' cost we used the best available proxy, as no billing system exists in Portugal, the "price" per hospitalization defined yearly by ACSS taking into consideration the diagnostic related groups methodology (all patients refined diagnosis related groups version 31.0) for the year 2017. Although this proxy might not represent the actual direct cost of ACSC it has been regularly used [38, 46-48]. The estimated 352 million euros represents $2 \%$ of the overall Portuguese healthcare expenditure [51]. According to the same source, the expenditure with public ambulatory care providers (excluding medication and diagnostic procedures) is 7.6\%. This means that ACSC hospitalizations could cost yearly around $25 \%$ of what is spent with public ambulatory care providers. In another perspective, using the Gouveia et al. [52] estimation for the price per consultation in the Portuguese Primary Health Care $(74.90 € /$ per consultation including medication and diagnostic procedures), the estimated cost of ACSC hospitalization would translate into more than 4,6 million consultations in $\mathrm{PHC}$, around $15 \%$ of all consultations that occurred in 2017 [53]. It is noteworthy that this exercise of cost-opportunity cannot be entirely fulfilled given that not all ACSC hospitalizations can be avoided.

The development of a validated list for the Portuguese context is important, as the use of a common methodology can standardize results, enhancing comparability within the country. The use of the country-specific list can also better reflect the health system organization and population characteristics of Portugal, therefore with a higher specificity to the Portuguese context. It does however hinder international comparability. Having validated an ACSC list for the Portuguese setting it is expected that henceforward official authorities and academic research use this list when measuring ACSC hospitalizations.
Finally, it is important to address some limitations inherent not only to this paper, but also to the concept and operationalization of ACSC as an indicator of access and quality of care.

The use of experts' opinion in the definition of ACSCs is subject to several biases, as well as the process of translating conditions into diagnosis codes. Furthermore, the use of administrative databases intended for financial purposes and subject to coding quality variations also recommends precaution in the interpretation of the results herein described. Such limitation is inherent to studies using these databases, as recognized by previous studies [38, 54, 55]. However, these variations should not be relevant enough to compromise the overall picture, but should be taken into account when trying to zoom in to lower levels of aggregation. For example, while at the national and regional level this indicator is useful to identify Public Health priorities it might not be adequate at the local and individual level to evaluate specific providers' access and quality once the aforementioned biases may cause an important lack of specificity. It is commonly discussed in ACSC studies that this indicator of quality of care does not apply to the individual experience of the patient and the medical practice $[2,56,57]$.

The regional and local use should also take into account several determinants of ACSC hospitalizations, such as socioeconomic status, hospital distance and rurality [58-61], disease and multimorbidity prevalence [9], in order to achieve a necessary risk adjustment of results.

\section{Conclusion}

We have developed a list of ACSCs for Portugal. This list includes conditions not identified in previous methodologies and excludes others previously identified thus increasing the specificity to the Portuguese context. Using this list to identify ACSC hospitalizations in Portugal, we have found a higher number of hospitalizations than what was estimated by previous studies. It is expected that this list could be used henceforward by epidemiologic studies, health services research and for healthcare management purposes. The identification of four new conditions contributes to the update of ACSC definition, highlighting that ACSC lists need to be frequently revisited and updated to keep up with technological and knowledge advances. Further research is necessary to increase the specificity of ACSC as an indicator of healthcare quality in smaller scales of analysis, such as individual or grouped providers. To increase this specificity, it will be necessary to determine how specific patient and context variables interact with each other in the pathway resulting in a ACSC hospitalization. 


\section{Abbreviations}

ACSC: Ambulatory Care Sensitive Conditions; ACSS: Administração Central do Sistema de Saúde; APMGF: Portuguese Association of General and Family Medicine; COPD: congestive obstructive pulmonary disease; $\mathrm{CIHI}$ : Canadian Institute for Health Information; GP: General practitioners; HBV: Hepatitis B virus; HIV: Human immunodeficiency virus; ICD10: International Classification of Diseases 10th Version; IM: Internal Medicine physicians; JS: João Sarmento; SPMI: Portuguese Society of Internal Medicine; RS: Rui Santana

\section{Acknowledgements}

We acknowledge the Central Administration of the Health System for providing the hospital morbidity database.

We acknowledge the scientific societies for the selection and invitation of experts, namely the Portuguese Association of General and Family Medicine (APMGF) and the Portuguese Society of Internal Medicine (SPMI).

We acknowledge the experts that concluded the Delphi panel: Alberto Pinto Hespanhol, Alexandra Fernandes, Ana Margarida Antunes Cruz, Ana Nunes Barata, André Biscaia, Armado Brito Sá, Bruno Heleno, Conceição Félix Machado, Daniel Pinto, David Rodrigues, Fernando Salvador, Jaime Correia de Sousa, Jorge Crespo, José Augusto Simões, José Mendes Nunes, Lino Ministro, Luís Costa Matos, Luís Miguel Santiago, Luís Pisco, Miguel Pereira, Mónica Granja, Nelson Rodrigues, Nuno Jacinto, Pascale Charondiere, Paula Broeiro, Pedro Fonte, Sofia Azevedo, Susana Medeiros, Vítor Branco. We acknowledge the precious help of João Iglésias with the information technologies.

\section{Authors' contributions}

JS: Research design; Literature review; Original data collection; Manuscript writing reviewing and editing. JVMR: Literature review; Manuscript writing reviewing and editing. RS: Research design; Original data collection; Manuscript writing reviewing and editing. All authors have read and approved the manuscript.

\section{Funding}

None to declare.

\section{Availability of data and materials}

The datasets used and/or analysed during the current study are available from the corresponding author on reasonable request.

\section{Ethics approval and consent to participate}

The research protocol was approved by the National School of Public Health Ethics approval was waived by the National School of Public Health institutional review board.

The utilization of the data for the present study was authorized by both the Portuguese Central Administration of the Health System and the National School of Public Health.

Once the participation of experts implied repeated answering of online questionnaires, the consent to participate was implicit should an answer be provided. No formal consent was required for this reason.

\section{Consent for publication}

Not applicable.

\section{Competing interests}

The authors declare that they have no competing interests.

\section{Author details}

'NOVA National School of Public Health, Public Health Research Center, Universidade NOVA de Lisboa, Av. Padre Cruz, 1600-560 Lisbon, Portugal. ${ }^{2}$ Comprehensive Health Research Center, Universidade NOVA de Lisboa, Lisbon, Portugal.

Received: 9 March 2020 Accepted: 3 August 2020

Published online: 15 August 2020

\section{References}

1. Billings J, Zeitel L, Lukomnik J, Carey TS, Blank AE, Newman L. Impact of socioeconomic status on hospital use in New York City. Health Aff. 1993; 12(1):162-73. https://doi.org/10.1377/hlthaff.12.1.162.
2. Nedel FB, Facchini LA, Bastos JL, Martín M. Conceptual and methodological aspects in the study of hospitalizations for ambulatory care sensitive conditions. Cien Saude Colet. 2011;16(Suppl 1):1145-54. https://doi.org/10. 1590/S1413-81232011000700046.

3. Caminal J, Mundet X, Ponsà JA, Sánchez E, Casanova C. Las hospitalizaciones por ambulatory care sensitive conditions: selección del listado de códigos de diagnóstico válidos para España. Gac Sanit. 2001;15(2): 128-41. https://doi.org/10.1016/S0213-9111(01)71532-4.

4. Ansari Z, Barbetti T, Carson NJ, Auckland MJ, Cicuttini F. The Victorian ambulatory care sensitive conditions study: rural and urban perspectives. Soz Praventivmed. 2003;48(1):33-43. https://doi.org/10.1007/s000380300004.

5. Roos LL, Walld R, Uhanova J, Bond R. Physician visits, hospitalizations, and socioeconomic status: ambulatory care sensitive conditions in a Canadian setting. Published online 2005:1167-1185. doi:https://doi.org/10.1111/j.14756773.2005.00407.x

6. Pirani M, Schifano P, Agabiti N, Davoli M, Caranci N, Perucci CA. Potentially avoidable hospitalisation in Bologna, 1997-2000: temporal trend and differences by income level. Epidemiol Prev. 2006;30(3):169-77.

7. Agabiti N, Pirani M, Schifano P, et al. Income level and chronic ambulatory care sensitive conditions in adults: a multicity population-based study in Italy. BMC Public Health. 2009;9(1):457. https://doi.org/10.1186/1471-2458-9457.

8. Magan P, Otero A, Alberquilla A, Ribera JM. Geographic variations in avoidable hospitalizations in the elderly, in a health system with universal coverage. BMC Health Serv Res. 2008;8(1):42. https://doi.org/10.1186/14726963-8-42.

9. Dantas I, Santana R, Sarmento J, Aguiar P. The impact of multiple chronic diseases on hospitalizations for ambulatory care sensitive conditions. BMC Health Serv Res. 2016;16(1):348. https://doi.org/10.1186/s12913-016-1584-2.

10. Rizza P, Bianco A, Pavia M, Angelillo IF. Preventable hospitalization and access to primary health care in an area of southern Italy. BMC Health Serv Res. 2007;7(1):134. https://doi.org/10.1186/1472-6963-7-134.

11. Menec VH, Sirski M, Attawar D, Katz A. Does continuity of care with a family physician reduce hospitalizations among older adults? J Heal Serv Res Policy. 2006;11(4):196-201. https://doi.org/10.1258/135581906778476562.

12. Purdy S, Griffin T, Salisbury C, Sharp D. Ambulatory care sensitive conditions: terminology and disease coding need to be more specific to aid policy makers and clinicians. Public Health. 2009;123(2):169-73. https://doi.org/10. 1016/j.puhe.2008.11.001.

13. Brown A, Goldacre M, Hicks N, et al. Hospitalization for ambulatory care sensitive conditions: a method for comparative access and quality studies using routinely collected statistics. Can J Public Heal. 2001;92(2):155-9.

14. Canadian Insititute of Health Information. Health Indicators 2008: CIHI; 2008.

15. Page A, Ambrose S, Glover J, Hetzel D. Atlas of avoidable Hospitalisations in Australia: ambulatory care-sensitive conditions. Adelaide: PHIDU, University of Adelaide; 2007.

16. Alfradique ME, Bonolo PDF, Dourado I, et al. Internações por condições sensíveis à atenção primária: a construção da lista brasileira como ferramenta para medir o desempenho do sistema de saúde (Projeto ICSAP - Brasil). Cad Saude Publica. 2009;25(6):1337-49. https://doi.org/10.1590/ S0102-311X2009000600016.

17. Freund T, Campbell S, Geissler $S$, et al. Strategies for reducing potentially avoidable hospitalizations for ambulatory care sensitive conditions. Ann Fam Med. 2013;11(4):363-70. https://doi.org/10.1370/afm.1498.

18. Sundmacher L, Fischbach D, Schuettig W, Naumann C, Augustin U, Faisst C. Which hospitalisations are ambulatory care-sensitive, to what degree, and how could the rates be reduced? Results of a group consensus study in Germany. Health Policy (New York). 2015;1 19(11):1415-23. https://doi.org/10. 1016/j.healthpol.2015.08.007.

19. Agency for Healthcare Research and Quality. Prevention Quality Indicators Overview. Published 2018. http://www.qualityindicators.ahrq.gov/modules/ pqi_resources.aspx.

20. Solberg LI, Peterson KE, Ellis RW, et al. The Minnesota project : a focused approach to ambulatory quality. Inquiry. 1990;27(4):359-67.

21. Weissman JS, Gatsonis C, Epsein AM. Rates of avoidable hospitalization by insurance status in Massachusetts and Maryland. JAMA. 1992;268(17):238894. https://doi.org/10.1001/jama.1992.03490170060026.

22. World Health Organization Regional Office for Europe. Assessing Health Services Delivery Performance with Hospitalizations for Ambulatory Care Sensitive Conditions. Copenhagen: Health Services Delivery Programme, Division of Health Systems and Public Health; 2016. 
23. Carinci F, Gool K, Mainz J, et al. Towards actionable international comparisons of health system performance : expert revision of the OECD framework and quality indicators. Int J Qual Heal Care. 2015;27(March):13746. https://doi.org/10.1093/intghc/mzv004.

24. Marshall M, Leatherman S, Mattke S, Panel M of the OHPP and PC. Selecting Indicators for the Quality of Health Promotion, Prevention and Primary Care at the Health Systems Level in OECD Countries.; 2004. https://www.oecd. org/els/health-systems/33865865.pdf.

25. NHS England. Quality and outcomes framework. Published 2019. Accessed February 18, 2020. https://digital.nhs.uk/data-and-information/publications/ statistical/quality-and-outcomes-framework-achievement-prevalence-andexceptions-data/2018-19-pas.

26. Harrison MJ, Dusheiko M, Sutton M, Gravelle H, Doran T, Roland M. Effect of a national primary care pay for performance scheme on emergency hospital admissions for ambulatory care sensitive conditions: controlled longitudinal study. BMJ. 2014;349(nov11 1):g6423. https://doi.org/10.1136/ bmj.g6423.

27. Agency for Healthcare Research and Quality. Guide to Prevention Quality Indicators: Hospital Admission for Ambulatory Care Sensitive Conditions. 2001. https://www.ahrq.gov/downloads/pub/ahrqqi/pqiguide.pdf.

28. Dourado I, Oliveira VB, Aquino R, et al. Trends in primary health caresensitive conditions in Brazil: the role of the family health program (project ICSAP-Brazil). Med Care. 2011;49(6):577-84. https://doi.org/10.1097/MLR. 0b013e31820fc39f

29. Administração Central do Serviço de Saúde. Operacionalização Da Contratualização de Cuidados de Saúde Primários 2018. 2017. http://www.acss. min-saude.pt/wp-content/uploads/2017/12/Operacionalizacao_CSP_2018.pdf.

30. Sarmento J, Santana R. Defining the ambulatory care sensitive conditions in Portugal: methodology description. Int J Integr Care. 2015;15(5):3-4.

31. Rocha JVM, Nunes C, Santana R. Avoidable hospitalizations in Brazil and Portugal: Identifying and comparing critical areas through spatial analysis. PLoS One. 2019;14(7):1-16 doi:e0219262.

32. Silva ARV. Internamentos por Causas Sensíveis a Cuidados de Ambulatório: Qual a influência das características de organização dos cuidados de saúde primários? Published online 2015.

33. Dimitrovová K, Costa C, Santana P, Perelman J. Evolution and financial cost of socioeconomic inequalities in ambulatory care sensitive conditions : an ecological study for Portugal , 2000-2014. Int J Equity Health. 2017;16(145): 1-11. https://doi.org/10.1186/s12939-017-0642-7.

34. Venancio MJS. Os internamentos devidos a Ambulatory Care Sensitive Conditions em Portugal: Caracterização e variabilidade espacial em 2013 e 2014. Published online 2016.

35. Tello J, Santana R, Sarmento J, et al. Ambulatory Care Sensitive Conditions in Portugal.; 2016. http://www.euro.who.int/en/countries/portugal/ publications2/ambulatory-care-sensitive-conditions-in-portugal-2016.

36. Sarmento J, Alves C, Oliveira P, Sebastião R, Santana R. Caracterização e Evolução dos Internamentos Evitáveis em Portugal: Impacto de Duas Abordagens Metodológicas. Acta Medica Port. 2015;28(5):590-600.

37. Bourret R, Mercier G, Mercier J, et al. Comparison of two methods to report potentially avoidable hospitalizations in France in 2012 : a cross-sectional study. BMC Health Serv Res. 2015;15(1):1-8. https://doi.org/10.1186/s12913014-0661-7.

38. Weeks WB, Ventelou B, Paraponaris A. Rates of admission for ambulatory care sensitive conditions in France in 2009-2010: trends, geographic variation, costs, and an international comparison. Eur J Health Econ. 2016; 17(4):453-70. https://doi.org/10.1007/s10198-015-0692-y.

39. Gaspar CSA. Os internamentos evitáveis múltiplos em Portugal: caracterização e fatores associados. Published online 2018.

40. Ministry of Health of New Zealand. Health and Independence Report: Director-General's Annual Report on the State of Public Health. 2003.

41. Organization for Economic Co-operation and Development. Health at a Glance 2017: OECD Indicators. OECD Publishing, Paris; 2017. doi:https://doi. org/10.1787/health_glance-2017-en.

42. Sanderson C, Dixon J. Conditions for which onset or hospital admission is potentially preventable by timely and effective ambulatory care. J Health Serv Res Policy. 2000;5(4):222-30. https://doi.org/10.1177/ 135581960000500407.

43. Walker JD, Teare GF, Hogan DB, et al. Facilities linked references are available on JSTOR for this article : identifying potentially avoidable hospital admissions from Canadian long-term care facilities. Med Care. 2009:47(2): 250-4.
44. Eggli Y, Desquins B, Seker E, Halfon P. Comparing potentially avoidable hospitalization rates related to ambulatory care sensitive conditions in Switzerland: the need to refine the definition of health conditions and to adjust for population health status. BMC Health Serv Res. 2014;14(1):25. https://doi.org/10.1186/1472-6963-14-25.

45. Naumann C, Augustin U, Sundmacher L. Ambulatory care-sensitive conditions in Germany: A small area analysis (2006-2009). Gesundheitswesen Published online 2014. doi:https://doi.org/10.1055/s0034-1372576.

46. Tian Y, Dixon A, Gao H. Data Briefing - Emergency Hospital Admissions for Ambulatory Care-Sensitive Conditions: Identifying the Potential for Reductions; 2012.

47. Sheridan A, Howell F, Bedford D. Hospitalisations and costs relating to ambulatory care sensitive conditions in Ireland. Ir J Med Sci. 2012;181(4): 527-33. https://doi.org/10.1007/s11845-012-0810-0.

48. de Souza DK, Peixoto SV. Estudo descritivo da evolução dos gastos com internações hospitalares por condições sensíveis à atenção primária no Brasil, 2000-2013. Epidemiol e Serviços Saúde. 2017;26(2):285-94. https://doi. org/10.5123/S1679-49742017000200006.

49. Ministério da Saúde- Diário da República. Portaria n. ${ }^{\circ}$ 234/2015. https://dre. pt/application/conteudo/69968713.

50. Rocha JVM, Marques AP, Moita B, Santana R. Direct and lost productivity costs associated with avoidable hospital admissions. BMC Health Serv Res. 2020;20(210):1-9. https://doi.org/10.1186/s12913-020-5071-4.

51. Instituto Nacional de Estatística. Conta Satélite da Saúde 2015-2017. Destaque - informação à Comun Soc. Published online 2018:2015-2017. file:///C:/Users/ensp/Downloads/26CSS_2017PT.pdf.

52. Gouveia M, Borges M, Augusto M, Ascensão R. Transferências de Cuidados de Saúde Prestados Em Meio Hospitalar Para as Redes de Cuidados Primários e Continuados.; 2012. https://www.aped-dor.org/images/diversos/ documentos/relatorio_transferencia_servicos_hospitalares_cuidados_ primarios_saude.pdf.

53. Administração Central do Sistema de Saúde. SNS continua a aumentar a atividade assistencial em 2018. Published 2019. Accessed July 20, 2020. http://www.acss.min-saude.pt/2019/02/14/sns-continua-a-aumentar-aatividade-assistencial-em-2018/

54. Chau PH, Woo J, Gusmano MK, et al. Health Economics, Policy and Law Access to primary care in Hong Kong, Greater London and New York City. Heal Econ Policy Law. 2013;8(10):95-109. https://doi.org/10.1017/ S1744133112000114

55. Kim H, Cheng S. Assessing quality of primary diabetes care in South Korea and Taiwan using avoidable hospitalizations. Health Policy (New York). 2018, 122(11):1222-31. https://doi.org/10.1016/j.healthpol.2018.09.009.

56. Caminal J, Sánchez E, Morales M, Peiró R, Márquez S. Advances of the investigation of "ambulatory care sensitive conditions" in primary care in Spain. Rev Esp Salud Publica. 2002;76(3):189-96.

57. Longman JM, Passey ME, Ewald DP, Rix E, Morgan GG. Admissions for chronic ambulatory care sensitive conditions - a useful measure of potentially preventable admission? BMC Health Serv Res. 2015;15(1):472. https://doi.org/10.1186/s12913-015-1137-0.

58. Berlin C, Busato A, Rosemann T, Djalali S, Maessen M. Avoidable hospitalizations in Switzerland: a small area analysis on regional variation, density of physicians, hospital supply and rurality. BMC Health Serv Res. 2014;14(1):289. https://doi.org/10.1186/1472-6963-14-289.

59. Huntley A, Lasserson D, Wye $L$, et al. Which features of primary care affect unscheduled secondary care use? A systematic review. BMJ Open. 2014;4(5): e004746. https://doi.org/10.1136/bmjopen-2013-004746.

60. Busby J, Purdy S, Hollingworth W. How do population, general practice and hospital factors influence ambulatory care sensitive admissions: a cross sectional study. BMC Fam Pract. 2017:1-9. https://doi.org/10.1186/s12875017-0638-9 Published online.

61. Sentell TL, Seto TB, Young MM, et al. Pathways to potentially preventable hospitalizations for diabetes and heart failure: a qualitative analysis of patient perspectives. BMC Health Serv Res. 2016;16(1):300. https://doi.org/10. 1186/s12913-016-1511-6.

\section{Publisher's Note}

Springer Nature remains neutral with regard to jurisdictional claims in published maps and institutional affiliations. 